\title{
Implicit need for achievement moderates the relationship between competence need satisfaction and subsequent motivation ${ }^{\text {is }}$
}

\author{
Julia Schüler $^{\mathrm{a}, *}$, Kennon M. Sheldon ${ }^{\mathrm{b}}$, Stephanie M. Fröhlich ${ }^{\mathrm{c}}$ \\ ${ }^{a}$ University of Zürich, Department of Psychology, Binzmühlestrasse 14/6, 8050 Zürich, Switzerland \\ ${ }^{\mathrm{b}}$ University of Missouri-Columbia, Department of Psychology, 112 McAlester Hall, Columbia, MO 65211, USA \\ ${ }^{\mathrm{c}}$ University of Osnabrueck, Institut of Rehabilitation Research Norderney e.V., Department of Bad Rothenfelde, Rehaclinic Muensterland, Auf der Stöwwe 11, \\ 49214 Bad Rothenfelde, Germany
}

Keywords:

Self-determination theory

Achievement motive

Optimal motivation

Goal commitment

\begin{abstract}
A B S T R A C T
Self determination theory (SDT) proposes that all humans have a need for competence. But is this need modulated by individual differences? Our research integrated SDT, which defines psychological needs (including competence) as universally essential experiences, and motive disposition theories, which define psychological needs as individually varying non conscious motives. A cross sectional and a longi tudinal study showed that felt competence in a sports activity has especially positive effects on subse quent flow and intrinsic motivation for individuals high in the need for achievement. Study 3 showed that felt competence more strongly influences subsequent academic goal motivation for those high in the need for achievement. Discussion focuses on the importance of integrating universalist and individual difference approaches to motivation, to derive the most complete understanding.
\end{abstract}

\section{Introduction}

Positive forms of motivation such as intrinsic motivation, flow and a high commitment to one's personal goals are connected to positive outcomes such as well being and performance, and there fore their prediction is the aim of a variety of theories (Brunstein, Schultheiss, \& Grässmann, 1998; Csikszentmihalyi, Abuhamdeh, \& Nakamura, 2005; Deci \& Ryan, 1985). However, these theories are often unconnected so far and synergies that could result from an integrative perspective remain unused. The present research at tempted to integrate two influential theories of human needs, in order to predict optimal situational motivation. The first is the ba sic need approach proposed by self determination theory (SDT; Deci \& Ryan, 1985, 2000). Here, the psychological needs for auton omy, competence and relatedness are conceptualized as innate ba sic requirements of all human beings that, when fulfilled, lead to intrinsic motivation and well being. The main focus of SDT re search has been to measure the level of need satisfaction currently experienced, and to use these variations to predict variations in po sitive outcomes such as intrinsic motivation and mood.

The second approach to human needs is the motive dispositions approach, as for example represented in McClelland and col league's research tradition (McClelland, 1985). Here, human needs

\footnotetext{
Study 3 was supported by a Research Grant from the DFG (KU 377/26-1) awarded to Julius Kuhl, University of Osnabrueck, Germany.

* Corresponding author. Fax: +41446357519.

E-mail addresses: j.schueler@psychologie.uzh.ch (J. Schüler), SheldonK@missouri.edu (K.M. Sheldon), Froehlich.ifr@klinik-muensterland.de (S.M. Fröhlich).
}

(also called implicit motives) such as the needs for achievement, affiliation and power are conceptualized as early acquired and rel atively stable motive dispositions that vary from person to person. The main focus of this research approach has been to measure indi vidual differences in particular needs, typically via projective methodologies such as the Thematic Apperception Test (TAT; Mur ray, 1943), and to use these variations to predict variations in per ception and behavior.

Although these two research approaches define psychological needs differently, they still deal with related topics. For example, the need for competence according to SDT involves the importance of experiencing oneself as able and effective in dealing with the environment (Sheldon, Elliot, Kim, \& Kasser, 2001) and the need for achievement according to the motive dispositions approach in volves the recurrent desire to "become better" and to improve one's skills while successfully interacting with the environment (McClelland, Atkinson, Clark, \& Lowell, 1953). Despite their obvious thematic similarity there have been few attempts to integrate these traditions so far. The present research asked whether indi vidual differences in the need for achievement amplify the predic tive power of competence need satisfaction on intrinsic and goal motivation. Below, the main assumptions of the two approaches will be briefly summarized.

\subsection{Basic needs within the SDT approach}

SDT researchers define intrinsic motivation as "doing a behavior because the activity itself is interesting and spontaneously 
satisfying. When intrinsically motivated, people perform activities because of the positive feelings resulting from the activities them selves" (Deci \& Ryan, 2008, p. 15). Given the importance of intrinsic motivation for many positive outcomes, it is important to know how to support it. According to SDT, intrinsic motivation within a context tends to be enhanced when people get their psychological needs met within that context specifically, then they feel autono mous, competent, and related (Deci \& Ryan, 2000). The need for autonomy "concerns people's universal urge to be causal agents, to experience volition, to act in accord with their integrated sense of self (i.e., with their interests and values)" (Deci \& Vansteenkiste, 2004 , p. 25). The need for competence is fulfilled when people feel that they are capable and effective in their actions rather than feel ing incompetent or ineffective (Sheldon et al., 2001). The need for relatedness is the desire to feel connected to others, to care for oth ers and to feel cared for by others (Baumeister \& Leary, 1995).

Deci and Ryan $(1985,2000)$ conceptualized basic needs as in nate rather than learned. The conceptualization of basic needs as "psychological nutriments that are essential for ongoing psycho logical growth, integrity, and well being" (Deci \& Ryan, 2000, p. 229 ) implies that their satisfaction "constitutes the central psycho logical process through which intrinsic motivation, the integrative tendency, and intrinsic goal pursuits are facilitated, resulting in well being and optimal development" (Deci \& Vansteenkiste, 2004, p. 26). In contrast, the frustration of basic needs leads to neg ative outcomes as for example impaired intrinsic motivation, well being, health and work performance (e.g., Deci \& Moller, 2007; Deci \& Ryan, 1985, 2008; Illardi, Leone, Kasser, \& Ryan, 1993). So cial environments that facilitate the satisfaction of the basic needs support individuals' natural tendencies to be active and to find sources of intrinsic motivation. In contrast, social contexts that thwart the basic needs, as for example controlling environments, hinder peoples' natural intrinsic motivation.

An impressive number of studies have confirmed the relation ship between the needs for autonomy, competence, and related ness and resultant intrinsic motivation and well being across different domains of human life (e.g., Baard, Deci, \& Ryan, 2004; Deci \& Ryan, 2000; Illardi et al., 1993; Kasser \& Ryan, 1999; Pelle tier, Fortier, Vallerand, \& Brière, 2001; Sheldon \& Krieger, 2007). For example, positive feedback, which satisfied people's need for competence, enhanced intrinsic motivation (Deci, 1971), whereas negative feedback thwarted felt competence satisfaction and de creased intrinsic motivation (Vallerand \& Reid, 1984; Vansteenk iste \& Deci, 2003).

\subsection{Needs within the motive disposition approach}

According to the motive disposition approach, situational moti vation is the consequence of a dispositional need interacting with an appropriate cue in the environment (or incentive) (cf. Beck mann \& Heckhausen, 2008; McClelland, 1985; Schneider \& Sch malt, 2000). Dispositional needs are conceptualized as acquired preferences for certain kinds of incentives (e.g., Atkinson, 1957; McClelland, Koestner, \& Weinberger, 1989; Murray, 1943; Schnei der \& Schmalt, 2000; Winter, 1973) and represent the "capacity to experience the attainment of a certain type of incentive as reward ing; as a consequence, it orients the individual towards cues re lated to the incentive and energizes and selects behavior aimed at incentive attainment" (Schultheiss \& Hale, 2007, p. 13).

The motive disposition approach mainly focuses on three mo tives, namely, the need for achievement (McClelland et al., 1953), the need for affiliation (McAdams \& Bryant, 1987) and the need for power (McClelland, 1985; Winter, 1973). The achievement mo tive is the recurrent concern with surpassing standards of excel lence (McClelland et al., 1953). The affiliation motive is defined as "the desire to establish and/or maintain warm and friendly interpersonal relations" (French \& Chadwick, 1956, p. 296) and is incentivized by the pleasure of being with other persons and exchanging contact with them (McClelland, 1987). The power mo tive is the desire to influence other persons, for example by arous ing strong emotions in others and to gain and maintain reputation and prestige (Winter, 1973).

The central assumption of the motive disposition approach is that motives differ in strength as a function of differences in early childhood learning and that these differences explain differences in the sensitivity toward certain kind of incentives and differences in behavior (for a summary see Schultheiss \& Hale, 2007). Individuals with a high need for achievement are very sensitive to the oppor tunity to do something better than before or than others and to im prove skills (Brunstein \& Heckhausen, 2008; McClelland, 1985). As a consequence they prefer challenging goals of moderate difficulty from which they get realistic feedback about their level of perfor mance and ability (Atkinson, 1957). For them, the striving for and attainment of achievement goals are accompanied by positive emotions such as enjoyment and proud. In contrast, the same class of situations is said to be much less attractive for individuals with a low achievement need. Additionally, low need for achievement individuals do not feel as many positive emotions while striving for and attaining the achievement goal. That is, they differ from high achievement motivated individuals in the capacity of getting satisfaction from seeking and attaining a particular type of incen tive (e.g., competence feeling) (McClelland, 1985; see also Brun stein et al., 1998).

An important theoretical distinction is between implicit and ex plicit motives which differ in terms of their developmental history, the incentives that arise the motives and the behavioral correlates (Brunstein, 2008; McClelland et al., 1989). Implicit motives are said to be non conscious and therefore are measured with projective (e.g., TAT; Murray, 1938) or semi projective measures (MMG; Sokolowski, Schmalt, Langens, \& Puca, 2000), whereas explicit mo tives are consciously represented self attributes and can be mea sured by participants' self reports for example by using the Personality Research Form (PRF; Jackson, 1984).

\subsection{Basic needs and individual motive differences}

So far, there has been little research that integrates the SDT and the motive disposition approaches to human needs in order to pre dict subsequent motivation. Additionally, there are at least two contrary theoretical positions regarding personality variables as moderators of the basic need satisfaction outcome relationship. On the one side, viewing needs as universal and innate, Deci and Ryan focus on environmental conditions that facilitate or hinder the satisfaction of basic needs which increase or decrease intrinsic motivation, rather then focussing on variations in need strength. Deci and Ryan (2000) acknowledged that people might vary in need strengths, but nevertheless came to the conclusion that "Although there may be individual differences in the strength of people's needs for competence, autonomy, and relatedness, we be lieve that these innate differences are not the most fruitful place to focus attention" (Deci \& Ryan, 2000, p. 232). On the contrary, Vall erand (2000) disagreed regarding this issue and stated that indi vidual differences in psychological needs are important to consider, because they could give information on the motivational processes underlying the relationship between basic need satisfac tion and its positive consequences. This assumption was supported by a study by Richer, Blanchard, and Vallerand (2002) in the affil iation domain showing that the relationship between social factors and motivation was mediated by the perception of relatedness and that this mediational relationship was moderated by the strength of the participants' dispositional need for relatedness. They concluded that "individual differences in needs may serve various 
functions, including that of determining which type of perceptions (autonomy, competence, relatedness) will influence motivation" (Vallerand, 2000, p. 316). Harackiewicz and colleagues (Hara ckiewicz, Sansone, \& Manderlink, 1985) found that participants high and low in the achievement motive responded differently (regarding task interest) to positive competence feedback which can be interpreted as need for competence satisfaction. However, further research is needed to shed light on the role of motives as moderators of the basic need satisfaction outcome relationship.

\subsection{Present research}

The present research aims at combining the main assumptions of SDT and the motive disposition approach in order to predict sub sequent motivation. We chose to focus upon the achievement do main in particular, because it has received the most attention within the motive disposition approach (McClelland, 1985). In accordance with SDT we hypothesized that feeling competent sat isfies an important human need and therefore will be associated with intrinsic motivation at a main effects level (hypothesis 1).

However, in accordance with the motive disposition research, we hypothesize that feeling competent has stronger effects for individuals with a higher need for achievement. Feeling competent ideally matches the desire of highly achievement motivated indi viduals to surpass a standard of excellence (McClelland, 1985) and therefore should produce the most intrinsic motivation to con tinue doing the activity in question. Conversely, the lack of felt competence (basic need thwarting), is more aversive to highly achievement motivated individuals and should produce low intrin sic motivation to continue doing the activity. In contrast, for indi viduals low in the need for achievement, feeling competent is expected to be somewhat less relevant and less predictive of sub sequent motivation for that activity.

We employed the Multi Motive Grid (MMG; Sokolowski et al., 2000), which measures implicit motives using an elegant and sim ple procedure which combines the advantages of projective and self report measures. Motive relevant pictures were presented with the aim to arouse participant's motives similar to the TAT (Murray, 1938, 1943) procedure. In contrast to the TAT measure, participants do not write down a complete story that later has to be coded by raters but answer statements that were presented along with the pictures. Because participants do not rate their own motives but instead project the motive relevant statements upon the situation illustrated in the picture, their unconscious mo tives can be measured (e.g., Gable, Reis, \& Elliot, 2003; Puca \& Sch malt, 2001; Schmalt, 1999; Sokolowski et al., 2000).

We conducted three studies to test the hypothesized interaction between the implicit need for achievement and felt competence, examining several measures of optimal situational motivation (flow experience, intrinsic motivation, goal commitment, goal pro gress), in both sport and academic domains.

\section{Study 1}

Study 1 used rated flow experience to operationalize optimal motivation. The flow experience is defined as a state "...that people report when they are completely involved in something to the point of forgetting time, fatigue, and everything else but the activity itself" (Csikszentmihalyi \& Rathunde, 1992, p. 59). Phenomenolog ically, it is a prototype of intrinsic motivation in which people feel totally involved in an activity and perform it for its own sake. According to Csikszentmihalyi (1990), flow experience results from an optimal balance of personal skills and task difficulty that enables people to act in a full sense of competence and control. Whereas the perceived lack of skills to manage the challenge of an activity leads to anxiety, being too skilled leads to boredom. The flow experience is conceptualized as a multifaceted phenomenon that includes full concentration on the task at hand, a high sense of control, a merging of action and awareness and an altered sense of time (Csikszentmihalyi et al., 2005). Due to the flow experience's rewarding experiential quality (Csikszentmihalyi et al., 2005) and its positive consequences for well being (e.g., Csikszentmihalyi \& LeFevre, 1989; Schüler, 2007) and performance (e.g., Csikszentmih alyi, Rathunde, \& Whalen, 1993; Engeser, Rheinberg, Vollmeyer, \& Bischoff, 2005), it is important to examine its determinants.

Again, in line with SDT research our first hypothesis was that flow experience is stronger for individuals whose need for compe tence is better satisfied. Secondly, we expected that this relation ship would be moderated by the implicit need for achievement. Individuals with a high need for achievement were expected to re port higher differences in flow depending on whether they feel competent or not than participants with a low need for achieve ment. Low achievement motivated individuals were also expected to show a significant benefit from feeling competent compared to not feeling competent (see hypothesis 1 ), but to a lesser degree than individuals with a high achievement motive.

Ryan and Deci (2000) criticized previous studies that have examined self reported motive as moderators (see above, Hara ckiewicz et al., 1985; Richer et al., 2002), stating that "part of the problem with assessing need strength as a moderator of the effects of satisfying the need also results from confusion between needs and their conscious representations" (Deci \& Ryan, 2000, p. 328). Self reported motives, which are conscious reflections about what a person needs that can be influenced by demands of the social environment and by inaccurate self theories, may not do the job of capturing "deep" motive dispositions and predicting how they moderate the effects of different types of experiences. In contrast, implicit motives better represent ingrained preferences than expli cit motives, because implicit motives are based on affect (rather than on cognition as are explicit motives), are developed early in life as a function of early rewarding experiences (rather than being formed by later self presentational processes), and are associated with intrinsic rather than explicit forms of motivation (see Brun stein, 2008). However, Deci and Ryan's criticism was made on con ceptual and not empirical grounds, and some research has shown the hypothesized moderator effect using self report motive mea sures (Harackiewicz et al., 1985). In order to empirically address this issue we measured achievement motives via both explicit and implicit methodologies, and hypothesized for theoretical rea sons that the competence $\times$ achievement moderator effect would be found only for the implicit achievement motive.

\section{Method Study 1}

\subsection{Participants and procedure}

One hundred and one undergraduate students at an American University took part in a study on "experiences in sports" in return for course credit. They were recruited at the end of a semester from university sport courses such as fitness, tennis and gymnastics courses. The sample comprised 87 women and 23 male with a mean age of 20.2 years $(S D=4.0)$. Participants completed a web based survey that contained the implicit and explicit motive mea sures and also asked them to rate their feelings of competence and flow experience regarding the relevant sports activity.

\subsection{Measures}

The satisfaction of the need for competence was measured with six items of the Basic Satisfaction of Needs Scale (e.g., Gagné, 
2003; Kashdan, Julian, Merritt, \& Uswatte, 2006) that was slightly adapted to the sport context (e.g., "Most times in doing my sport activity I felt a sense of accomplishment from what I do"). Partici pants were asked to refer the items to their sport courses in the current semester and responded to the items using a rating scale from 1 (not at all true) to 7 (very true) (Cronbachs' Alpha $=.75$.).

The implicit need for achievement was measured with the Multi Motive Grid (MMG; Sokolowski et al., 2000) which measures the hope and fear components of the achievement, affiliation and power motives. The MMG consists of 14 line drawings of everyday situations which are presented along with statements describing various thoughts, feelings, and action tendencies that participants had to rate regarding whether they fit with the situation or not. Participants are told that the pictures depict everyday situations and that they are not very clear and detailed because participants should use their imagination in guessing what might be going on in these pictures. They are informed that the experimenter is inter ested in the different ways people experience different situations and are asked to decide for each statement presented below the picture whether it describes the situation. If it does, participants should check "Yes", if it does not, they should check "No". They are asked to follow their spontaneous impressions and not to think to long about one statement. Examples of pictures are a person tak ing a test, a rope climber and a work group. Examples of achieve ment items are, "Feeling confident to succeed at this task" (hope of success) and "Thinking about lacking abilities at this task" (fear of failure). By using pictures to stimulate the motives, the MMG uses the same technique (apperception) as the TAT and therefore measures implicit motives. However by using pre specified state ments that participants have to rate, the motives can be assessed more consistently and more easily than with the time consuming TAT scoring procedure.

Still, one might criticize that using statements that have to be rated "explicitly" distorts the implicit character of the measure. This is unlikely due to four reasons. First and most importantly, Schmalt (1999) and Sokolowski et al. (2000) argued that in rating the persons in the picture (rather than themselves) participants project their non conscious motives into the situation, bypassing their explicit theories about themselves. Secondly, in contrast to the items used within explicit motive measures that usually pres ent descriptions of "your typical behavior," the MMG statements represent motivational tendencies in terms of cognitions, goal anticipation, and emotions that are consistent with the coding cat egories used in the TAT (and that would be scored as motive rele vant if written in TAT stories as for example using the coding system of McClelland et al., 1953). Third, correlations between MMG motives and explicit motives for example measured by the Personality Research Form (PRF) are typically low (Sokolowski et al., 2000). Fourth, the MMG predicts task enjoyment and intrin sic motivation which are theoretically associated with implicit rather than explicit motives (Deci \& Ryan, 2000).

Meanwhile, the validity of the MMG as an implicit motive mea sure has been repeatedly demonstrated (e.g., Gable, 2006; Gable et al., 2003; Kehr, 2004; Langens \& Schmalt, 2002; Puca, 2005; Puca, Rinkenauer, \& Breidenstein, 2006; Puca \& Schmalt, 1999, 2001; Schüler, 2007). For example, the need for achievement as sessed by the MMG predicted optimism (Puca \& Schmalt, 2001) and performance in achievement contexts (Puca \& Schmalt, 1999). The power motive is associated with leadership success (Sokolowski \& Kehr, 1999) and the affiliation motive predicted affiliation relevant behavior (Sokolowski et al., 2000). Furthermore, the hope and fear subscales predicted positive and negative well being, respectively (Gable, 2006; Langens \& Schmalt, 2002; Lan gens \& Schüler, 2005).

In traditional motivational theory, the positively valenced com ponent (e.g. hope of success) and the negatively valenced compo nent (e.g., fear of failure) of the implicit motive are both assumed to contribute to people's affect, motivation and behavior and thus both have to be considered in order to improve the predictive power of the motive score (Atkinson, 1964; Atkinson \& Feather, 1966; McClelland, 1992). For example, in Atkinson's (1957) risk taking model, achievement behavior is predicted by considering hope of success (an approach tendency that energizes behavior to ward optimally challenging tasks) as well as fear of failure (an avoidance tendency that causes people to choose either very easy or very difficult tasks). In order to take both factors into account, Atkinson computed a difference score of hope minus fear, which he called the "resultant tendency") (Atkinson, 1964; Atkinson \& Feather, 1966; McClelland, 1992). Based on Atkinson's reasoning, we assumed that fear of failure detracts from the positive effects of hope of success on subsequent motivation. This assumption is also in line with findings that fear is antithetical to flow experience (Csikszentmihalyi, 1990; Jackson, 1995) and undermines intrinsic motivation (Deci \& Ryan, 1985). Thus, we used a difference score approach by subtracting the $z$ transformed fear of failure score of the MMG (Cronbach's Alpha = .79) from the hope of success score (Cronbach's Alpha $=.68$ ). This and similar overall measures of mo tives have been shown to be highly valid in the achievement (Puca, 2005; Puca \& Schmalt, 2001; Schüler, 2007) and the affiliation do main (Schüler, Job, Fröhlich, \& Brandstätter, 2008). In the present study, Cronbach's Alpha for the hope of success items and the re coded fear of failure items was .80 , indicating a high reliability of the overall measure (Cronbachs' Alpha for hope of success, HS: .68; fear of failure, FF: .79; Pearson correlation HS and FF $=.35$, $p<.001$ ).

To measure the explicit need for achievement we used the achievement scale of a German version of Jacksons' (1984) Person ality Research Form (Stumpf, Angleitner, Wieck, Jackson, \& Beloch Till, 1985). Participants' could agree or disagree with 12 achieve ment statements as for example "My goal is to do at least a little bit more than anyone else has done before." After recoding items, an explicit achievement motive index was computed by summing the number of agreed with items (Cronbach's Alpha $=.70$ ).

The 10 item Flow Short Scale (Rheinberg, Vollmeyer, \& Engeser, 2003) was administered to measure flow experience, the depen dent measure. It consists of the two subscales of being absorbed by action ("I do not recognize that time is going by"; Cronbach $\alpha=.72$ ) and feeling automaticity in action ("I feel that everything is under control"; Cronbach $\alpha=.88$ ). Participants were asked to rate whether they agree with each item regarding to the sport courses they took part in the current semester (1: no agreement to 7: full agreement). In addition to the two flow subscale scores, an average score of flow experience was computed (Cronbach $\alpha=.90$; for this procedure see also Rheinberg \& Vollmeyer, 2003).

\section{Results}

\subsection{Preliminary analyses, descriptive statistics and correlations}

Preliminary analyses revealed that neither age nor sex of partic ipants influenced the results reported below, thus these subject variables will not be considered further. In accordance with the first hypothesis, correlational analyses showed a significant rela tionship between the satisfaction of need for competence $(M=4.83, S D=1.02)$ and flow experience $(M=4.72, S D=1.08)$, $r=.61 \quad(p<.01)$. Neither the implicit need for achievement $(M=.88, S D=4.25)$ nor the explicit need for achievement $(M=10.24, S D=3.06)$ were significantly correlated with need for competence satisfaction (implicit: $r=.15, n s$; explicit: $r=.02, n s$ ) and flow (implicit: $r=.13, n s$; explicit: $r=-.09, n s$ ). In accordance with typical findings (e.g., McClelland et al., 1989), the implicit 
Table 1

Hierarchical regression of flow experience on need for competence satisfaction and the implicit achievement motive (upper part of table) and on need for competence satisfaction and the explicit achievement motive (lower part) (Study 1).

\begin{tabular}{|c|c|c|c|c|c|}
\hline Step & Variable & $\Delta R^{2}$ & $d f$ & $\Delta F$ & $b^{a}$ \\
\hline \multirow[t]{3}{*}{1} & Main effects & 38 & 2,97 & $29.36^{* \cdots}$ & \\
\hline & $\begin{array}{l}\text { Need for competence } \\
\text { satisfaction (NC) }\end{array}$ & & & & $.63^{\cdots}$ \\
\hline & $\begin{array}{l}\text { Implicit achievement } \\
\text { motive }(\mathrm{ACH})\end{array}$ & & & & -.02 \\
\hline \multirow[t]{2}{*}{2} & $\mathrm{NC} \times \mathrm{ACH}$ & .04 & 1,97 & $7.26^{* *}$ & $.21^{* *}$ \\
\hline & Cumulative $R^{2}$ & .42 & 3,97 & $23.24^{\cdots}$ & \\
\hline \multirow[t]{3}{*}{1} & Main effects & 38 & 2,97 & $30.71 \cdots$ & \\
\hline & $\begin{array}{l}\text { Need for competence } \\
\text { satisfaction (NC) }\end{array}$ & & & & $.62^{\cdots}$ \\
\hline & $\begin{array}{l}\text { Explicit achievement } \\
\text { motive (ExACH) }\end{array}$ & & & & -.11 \\
\hline \multirow[t]{2}{*}{2} & $\mathrm{NC} \times \mathrm{EXACH}$ & .00 & 1,97 & .07 & .02 \\
\hline & Cumulative $R^{2}$ & .39 & 3,97 & $20.23^{\cdots}$ & \\
\hline
\end{tabular}

$a b$ is the standardized regression coefficient in the regression equation.

.. $p<.01$.

$\cdots p<.001$.

and explicit need for achievement measures were unrelated $(r=.13, n s)$.

\subsection{Moderation analyses}

In order to examine if and how the implicit need for achieve ment moderated the effect of competence need satisfaction on flow experience a hierarchical regression analysis was conducted. After centering continuous variables (as suggested by Cohen, Co hen, West, \& Aiken, 2003), the implicit need for achievement score and the competence satisfaction score were entered into the regression equation (Step 1), followed by the multiplicative inter action of the two variables (Step 2) (Table 1, upper part). As ex pected by hypothesis 1 , the main effect of felt competence reached significance in the prediction of flow, $b=.63, s e_{b}=.08$, $p<.001$. Also the interaction of felt competence and implicit need for achievement significantly predicted flow, $b=.20, s e_{\mathrm{b}}=.07$, $t(97)=2.69, p<.01$.

To explore the nature of this interaction, we used a procedure proposed by Cohen et al. (2003), in which values at one standard deviation above or below the mean of the predictor variables are entered in the regression equation. The interaction illustrated in Fig. 1 shows that individuals high in the need for achievement

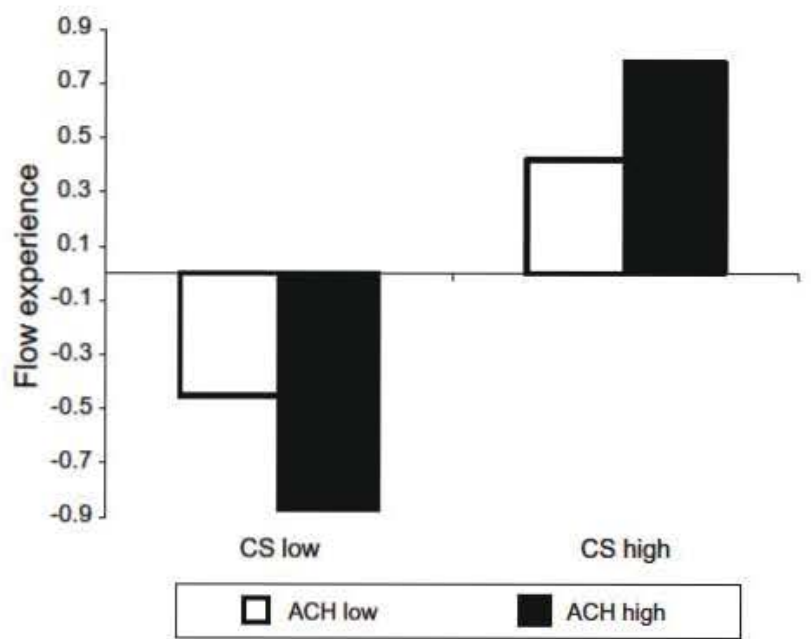

Fig. 1. Flow experience as a function of the need for competence satisfaction (CS) and implicit achievement motive (ACH) (Study 1). who feel competent report higher flow compared to individuals who do not feel competent and compared to low achievement motivated individuals with high competence satisfaction. The fig ure also shows that high achievement motivated individuals re ported the lowest flow of all when their need for competence was not fulfilled. Supplementary analyses revealed a very similar interaction pattern when considering the flow subscales sepa rately, rather than using the aggregated flow score (automaticity in action: $\beta=.23, b=.21, s e_{\mathrm{b}}=.08, t(97)=2.84, p<.01$; being $\mathrm{ab}$ sorbed by action: $\beta=.16, b=.15, s e_{\mathrm{b}}=.08, t(97)=1.90, p=.06$ ).

In order to test whether the explicit need for achievement mea sure also functioned as a moderator, we repeated the hierarchical regression analysis using the explicit instead of the implicit mea sure. Here, the regression of flow revealed no significant felt com petence $\times$ need for achievement interaction $\left(b=.02, s e_{b}=.06\right.$, $t(97)=.26, n s)$ (see lower part of Table 1$)$.

\section{Brief discussion}

The results confirmed our first hypothesis that participants whose need for competence was satisfied reported more flow than participants whose need for competence was not satisfied. This replicates the well known positive effects of basic need satisfac tion on optimal motivation reported in previous SDT research. The present results contribute to this research by showing that these effects are moderated by individual differences in the impli cit need for achievement. Besides the finding that individuals high in the need for achievement benefited more from feelings of com petence than individuals low in the achievement motive, we also learned that the former suffered more from need frustration than the latter.

Finally, as hypothesized, only the implicit need for achievement, but not the explicit need for achievement affected the link between feelings of competence and resultant feelings of flow. This is in line with the theoretical considerations on the characteristics of impli cit and explicit motives reported above, but nevertheless contra dicts the findings of a previous study in the achievement domain conducted by Harackiewicz et al. (1985) which revealed that expli cit achievement motivation moderates the relation between com petence need satisfaction and intrinsic interest (see above). One possible explanation for these discrepant findings is that Hara ckiewicz's design was especially activating of explicit motivation, in that adolescent students were being given performance evalua tions on an achievement task. Additionally, social comparison information was salient (e.g., the experiment was conducted in group sessions, and participants were asked how well they would do in comparison to other students). Social evaluation norms are known to be associated with self presentational motives (Brun stein, 2008) and are assumed to hinder rather than facilitate intrin sic motivation (Deci \& Ryan, 2000). In contrast, our methodologies were web surveys which did nothing to activate appearance or so cial comparison concerns. Another difference is that Harackiewicz et al. did not measure feelings of competence directly, but rather inferred such feelings based on the type of manipulated perfor mance feedback that was given. Further research is needed to examine the extent that different social and measurement contexts affect the relative predominance of implicit and explicit motives within those contexts; however, based on our Study 1 finding, in Studies 2 and 3 we will use implicit measures only.

\section{Study 2}

In Study 2 we tested whether the felt competence $\times$ implicit need for achievement interaction also predicts intrinsic motivation (and not just flow). We assessed feelings of competence using a 
different measure in order to ensure generalizability. The most important added value is that Study 2 was designed as a longitudi nal study in which we collected data at the beginning and at the end of a semester. We first analyzed the data on a cross sectional basis in order to replicate the primary results of Study 1. Extending these results, we also hypothesized that changes in need for com petence satisfaction from the beginning to the end of the semester correspond with changes in intrinsic motivation (hypothesis 1), especially for those high in the need for achievement (hypothesis 2).

\section{Method Study 2}

\subsection{Participants and procedure}

Seven hundred and fourteen students and alumni who planned to take part in sport courses such as aerobic, tennis and gymnas tics, offered by a sport organization at a Swiss university in the forthcoming semester, were invited to participate in a two part web survey. At the beginning of the semester (T1) participants were asked to complete the implicit achievement motive measure and the competence satisfaction measure. They also completed an intrinsic motivation questionnaire regarding the experience of exercising in the sport courses. Six hundred and eighty five under graduates (403 female; age: $M=32.00, S D=9.90$ ) also completed the second part of the web survey at the end of the semester (T2) and their data sets were included in the analyses reported be low. The second survey contained the second repeated measures of competence satisfaction and intrinsic motivation.

\subsection{Measures}

Competence need satisfaction was measured with a shortened version of the need for competence scale of the Psychological Need Satisfaction in Exercise Scale (PNSE; Wilson, Rogers, Rodgers, \& Wild, 2006). The English scale was translated into German by the first author and was back translated by an English native speaker. The back translated scale differed from the original scale in one minor point that was discussed by the native speaker and the first author. The German word which was responsible for the transla tion differences was replaced by a more appropriate word. For practical reasons the original scale had to be shortened. We choose four items that best represented the scale according to a factor analyses done by the test authors (Wilson et al., 2006). The items (e.g., "Capable of doing challenging exercises") had to be rated according to whether participants agree with the item using a Lik ert scale ranging from 1 (not at all) to 6 (very much) and the need for competence was highly reliable with Cronbach's Alpha $=.85$ at $\mathrm{T} 1$ and $\mathrm{T} 2$.

The implicit need for achievement was again measured using the Multi Motive Grid (MMG; Sokolowski et al., 2000) and again showed sufficient reliabilities (Cronbachs' Alpha for hope of suc cess: .73; fear of failure: .67; Pearson correlation HS and FF $=.13$, $p<.01)$. Cronbach's Alpha of the overall measure after recoding the fear of failure items was .62.

Intrinsic motivation was assessed using the intrinsic motivation scales of the Sport Motivation Scale (SMS, Pelletier et al., 1995) (e.g., "For the pleasure I feel in living exciting experiences"). Three items each from the intrinsic motivation to know scale, the intrin sic motivation to accomplish things scale and the intrinsic motiva tion to experience stimulation scale were chosen for the study and were aggregated to an overall mean score of intrinsic motivation. Participants rated their agreement using a 7 point scale (1: not at all to 7: very much) (Cronbach's Alpha $=.91$ at T1 and .92 at T2).

\section{Results Study 2}

\subsection{Preliminary analyses, descriptive statistics and correlations}

Neither age nor sex of participants influenced the results re ported below. Correlation analyses showed that need for compe tence satisfaction at $\mathrm{T} 1(M=5.03, S D=.80)$ and at $\mathrm{T} 2(M=4.88$, $S D=.79)$ positively correlated with the implicit achievement mo tive $(M=3.13, S D=3.45), r=.11(p<.05 ; \mathrm{T} 1)$ and $r=.10(p<.05$; T2) and with intrinsic motivation at T1 $(M=4.81, S D=1.32)$, $r=.37(p<.001 ; \mathrm{T} 1)$ and $r=.28(p<.001 ; \mathrm{T} 2)$ and with intrinsic motivation at T2 $(M=4.74, S D=1.28), r=.33(p<.001 ; \mathrm{T} 1)$ and $r=.40(p<.001$; T2). The implicit motive was uncorrelated with intrinsic motivation at both time of measurement (T1: $r=.03, n s$; $\mathrm{T} 2: r=.04 ; n s)$. Intrinsic motivation at $\mathrm{T} 1$ and at $\mathrm{T} 2$ were highly correlated, $r=.65, p<.001$.

\subsection{Cross sectional moderation analyses}

In order to replicate the cross sectional moderation effect we found in Study 1 (our second hypothesis), we employed the same hierarchical regression procedure and used the data collected at the end of a semester (as in Study 1). To examine the effects on intrinsic motivation at $\mathrm{T} 2$, we entered $\mathrm{T} 2$ competence satisfaction (CS) and the implicit need for achievement $(\mathrm{ACH})$ as a first step into the regression equation, followed by the $\mathrm{CS} \times \mathrm{ACH}$ interaction term (Step 2). As expected, a main effect of felt competence emerged, $\beta=.40, b=.40, s e_{\mathrm{b}}=.04, \Delta R^{2}=.16, p<.001$. Additionally, the inter action of felt competence and need for achievement predicted intrinsic motivation, $\beta=.10, b=.10, s e_{\mathrm{b}}=.04, \Delta R^{2}=.01$, $t(681)=2.87, p<.01$. The interaction pattern was similar to that of Study 1: High implicit need for achievement participants re ported more intrinsic motivation than individuals low in the impli cit achievement motive when they felt competent. Additionally, they were more intrinsically motivated when their need for com petence was fulfilled rather than when it was thwarted.

In order to test the robustness of the cross sectional moderation effect, we conducted the same regression analysis with the T1 measures. The regression of intrinsic motivation at T1 on compe tence satisfaction at $\mathrm{T} 1$ and the implicit need for achievement as Step 1 and the CS at T1 $\times \mathrm{ACH}$ as Step 2 revealed a significant main effect of felt competence at T1, $\beta=.37, b=.36, s e_{\mathrm{b}}=.03, \Delta R^{2}=.14$, $p<.001$. Additionally, the interaction of felt competence at T1 and need for achievement was significant, $\beta=.09, b=.08$, $s e_{\mathrm{b}}=.03, \Delta R^{2}=.01, t(681)=2.53, p=.01$.

\subsection{Longitudinal moderation analyses}

Because Study 2 was designed as a longitudinal study we could also test whether increases in felt competence in conjunction with (presumably stable) need for achievement predict changes in intrinsic motivation across the semester. Therefore, we predicted intrinsic motivation at the end of the semester by controlling for intrinsic motivation and felt competence at the beginning of the semester (Step 1). Felt competence (CS) at T2 and the implicit need for achievement $(\mathrm{ACH})$ were entered as Step 2 into the regression analysis followed by the $\mathrm{CS} \times \mathrm{ACH}$ interaction term (Table 2). The test retest effect of intrinsic motivation at $\mathrm{T} 1, b=.61, s e_{\mathrm{b}}=.03$, $p<.001$, as well as the main effect of need for competence satisfac tion at $\mathrm{T} 2, b=.24, s e_{\mathrm{b}}=.03, p<.001$, were significant. Thus, en hanced competence need satisfaction predicted enhanced intrinsic motivation, again supporting our first hypothesis. Addi tionally, the interaction of felt competence and need for achieve ment accounted for a significant amount of variance, $b=.06$, $s e_{\mathrm{b}}=.03, t(679)=2.09, p<.05$. The interaction pattern is illustrated 
Table 2

Hierarchical regression of intrinsic motivation at T2 (Study 2).

\begin{tabular}{|c|c|c|c|c|c|}
\hline Step & Variable & $\Delta R^{2}$ & df & $\Delta F$ & $b^{a}$ \\
\hline \multirow[t]{3}{*}{1} & Control variables & .44 & 2,682 & $267.81^{\cdots}$ & \\
\hline & $\begin{array}{l}\text { Need for competence } \\
\text { satisfaction, } \mathrm{T} 1\end{array}$ & & & & .00 \\
\hline & Intrinsic motivation, $\mathrm{T} 1$ & & & & $.58^{* \cdots}$ \\
\hline \multirow[t]{3}{*}{2} & Main effects & .04 & 2,680 & $26.55^{* \cdots}$ & \\
\hline & $\begin{array}{l}\text { Need for competence } \\
\text { satisfaction (CS), } \mathrm{T} 2\end{array}$ & & & & $.23^{\cdots}$ \\
\hline & $\begin{array}{l}\text { Implicit achievement } \\
\text { motive }(\mathrm{ACH})\end{array}$ & & & & .01 \\
\hline \multirow[t]{2}{*}{3} & $\mathrm{CS} \times \mathrm{ACH}$ & .003 & 1,679 & $4.37^{\circ}$ & $.06^{\circ}$ \\
\hline & Cumulative $R^{2}$ & .48 & 5,679 & $127.26^{\cdots *}$ & \\
\hline
\end{tabular}

${ }^{a} b$ is the standardized regression coefficient in the regression equation.

- $p<.05$.

$\cdots p<.001$.

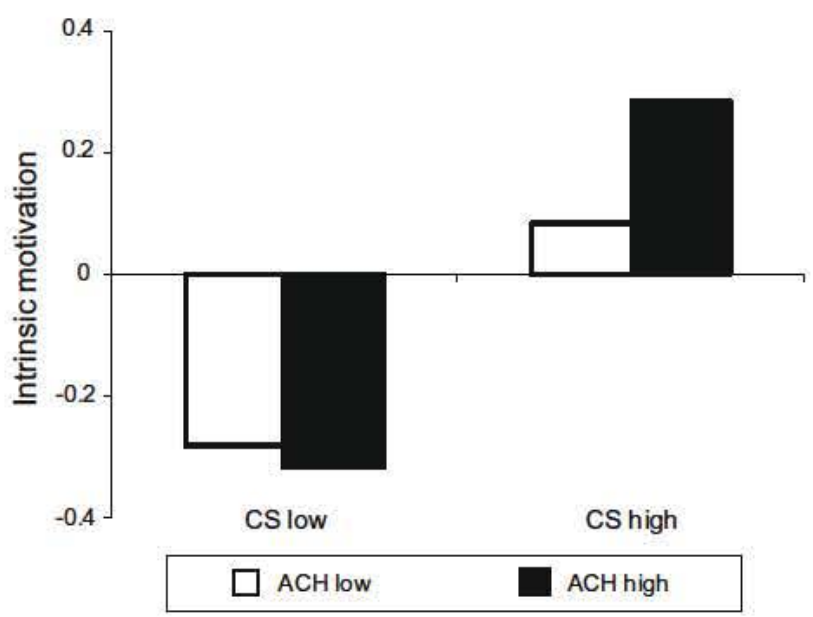

Fig. 2. Illustration of the need for competence satisfaction $\times$ implicit achievement motive effect on intrinsic motivation (longitudinal analysis, Study 2).

in Fig. 2 and indicates that individuals with a high need for achievement reported a greater increase in intrinsic motivation from the beginning to the end of the semester when their need for competence was satisfied compared to when it was thwarted and compared to low achievement motivated individuals with high competence satisfaction. ${ }^{1}$

\section{Brief discussion Study 2}

Using a larger sample and different measures of competence satisfaction and positive situational motivation, Study 2 replicated the cross sectional moderator effects found in the first study in which the implicit need for achievement variable moderated the effect of felt competence on intrinsic motivation. The longitudinal design of Study 2 also allowed us to test the hypotheses that in creased competence satisfaction from the beginning to the end of

\footnotetext{
${ }^{1}$ There is no clear way to examine correlated change with two-wave longitudinal designs. An alternative approach to the hierarchical regression analyses reported in the text is to compute difference scores (for a critical discussion of difference scores e.g., Willett, 1997). We computed difference scores by subtracting the T1 measures of competence satisfaction (CS) and intrinsic motivation from the $\mathrm{T} 2$ measures of CS and intrinsic motivation, respectively. The regression of increase of intrinsic motivation on the achievement motive (ACH) and the increase of CS (Step 1) and on the $\mathrm{ACH} \times$ increase of $\mathrm{CS}$ interaction (Step 2) revealed a significant main effect for increase of $\operatorname{CS}\left(\beta=.18, b=.18, s e_{\mathrm{b}}=.04, p<.001\right)$ and a significant interaction effect $\left(\beta=.08, b=.08, s e_{\mathrm{b}}=.04, t(681)=1.91, p<.05\right)$ which pattern is very similar to the one reported in the text, (Overall model: $R^{2}=.04, F(3,681)=8.68, p<.001$.)
}

a semester predicts increased intrinsic motivation, especially for those individuals high in the implicit need for achievement.

However, although the felt competence $\times$ achievement motive interactions were significant, the effect sizes were smaller than in Study 1 (in Study $1 \Delta R^{2}=.04$; in Study 2 cross sectional $\Delta R^{2}=.01$; longitudinal $\Delta R^{2}=.003$ ). One striking difference be tween the two studies was in the heterogeneity of the samples. Whereas in Study 1 only students of about the same age partici pated, the sample in Study 2 was much more diverse for instance regarding age (range from 19 to 67) and professional status (stu dents and alumni). This may account for the smaller effect sizes. Despite these varying effect sizes, the important thing to take away is that our hypotheses received significant support in both studies.

\section{Study 3}

Study 1 and Study 2 confirmed the hypothesized need satisfac tion $\times$ dispositional motive interaction in the domain of sport. To demonstrate the generalizability of the moderation effect across other domains of human life, in Study 3 we asked undergraduate students about their feelings of competence in the academic do main. To further enhance generalizability, we changed the motiva tion measure by asking our student sample about their motivation for striving for their personal academic goals. Therefore we as sessed goal commitment which is known as an effective motiva tional variable resulting in positive outcomes such as persistence in goal striving and well being (Brunstein, 1993; Hollenbeck \& Klein, 1987; Locke and Latham, 1990). Our assumption that need satisfaction and motive fulfillment, respectively, were not only connected to intrinsic motivation, but also to other subsequent forms of motivation to perform an activity, has been empirically supported in SDT research as well as in dispositional motive ap proach research. SDT researchers found for example that intrinsic need satisfaction predicted job related motivation as the time spent at work (Kasser, Davey, \& Ryan, 1992). Dispositional motive researchers showed for example that individual motive differences predicted absenteeism from work (Hackman \& Lawler, 1971). Additionally, researchers of both approaches showed that need sat isfaction is associated with performance, as for example perfor mance ratings at work (Baard et al., 2004), managerial effectiveness (McClelland \& Burnham, 1976) and work quality (Hackman \& Lawler, 1971).

Transferred to student's academic goals, we examined goal commitment as a subsequent motivation measure and perceived goal progress as a performance measure. We expected that feeling competent results in higher academic goal commitment and goal progress (hypothesis 1 ). Additionally we hypothesized that this relationship is moderated by the strength of the implicit achieve ment motive as assumed in Study 1 and Study 2 (hypothesis 2).

\section{Method Study 3}

\subsection{Participants and procedure}

One hundred and six students of the University of Osnabrueck, Germany, were invited to participate in a longitudinal study about "personality and goals." At the beginning of the semester (T1) par ticipants completed the implicit need for achievement measure and named and described six personal goals in a questionnaire at home. Due to practical reasons the baseline measures of need for competence satisfaction, goal commitment and goal progress took place seven weeks later (T2, middle of semester). At the end of semester (again 7 weeks later; T3) participants rated their compe tence need satisfaction, their current goal commitment and their goal progress for a second time. Fifty eight undergraduate students 
(45 female; age: $M=23.97, S D=4.90$ ) completed all three parts of the survey and their data sets were included in the analyses re ported below. These 58 participants did not differ in any variable measured at $\mathrm{T} 1$ from the 48 participants that decided to quit. The participation in the study was paid with $30 €$ or course credit.

\subsection{Measures}

Competence need satisfaction was measured by the daily activ ity based methodology used by Sheldon, Ryan, \& Reis et al. (1996; Reis, Sheldon, Gable, Roscoe, \& Ryan, 2000). This methodol ogy focuses participants upon the $24 \mathrm{~h}$ previous to the assessment rather than on life in general at the time of assessment. In the pres ent research we assessed participants' goal related activities on three different days during the semester, as random samples of their typical goal related activities during the semester. This more molecular focus likely explains the low test retest coefficients observed.

The implicit need for achievement was again measured using the Multi Motive Grid (MMG; Sokolowski et al., 2000) and again showed adequate reliabilities (Cronbachs' Alpha for HS: .67; FF: .72; overall score after recoding the fear of failure items: .66; Pear son correlation $\mathrm{HS}$ and $\mathrm{FF}=.06, n s$ ).

\subsection{Commitment to achievement goals}

At time 1 (T1), participants were asked to freely list six personal goals they want to strive for in the next months. Participants listed goals in different domains, for example leisure time goals, sport goals and academic goals. The scoring of the achievement goals was based on the coding system proposed by Kuhl and Scheffer (1999). It was carried out by a well trained psychologist who had reached high reliability with other coders in prior studies. Achieve ment goal commitment was assessed at the middle (T2) and the end of the semester (T3) by averaging, across the participants' coded achievement goals, ratings of the six commitment items (e.g. "No matter what happens, I will not give up this goal" used by Brunstein (1993; Brunstein et al., 1998). The items had to be rated using a 7 point scale from (1) I completely disagree to (7) I completely agree (7). Cronbachs' Alpha in this study was .77 at $\mathrm{T} 2$ and .81 at T3.

Progress in achievement goals was assessed simultaneously with goal commitment in a manner similar to Brunsteins' (1993; Brun stein et al., 1998) procedure in which six items of the subscales advancement, outcome and obstacles were computed to a goal progress score (item example: "I have made a great deal of pro gress in the attempt of advancing this goal"). The items had to be rated using a 7 point scale ranging from (1): I completely disagree to (7): I completely agree. Cronbachs' Alpha in this study was .79 at $\mathrm{T} 2$ and $\mathrm{T} 3$.

\section{Results Study 3}

\subsection{Preliminary analyses, descriptive statistics and correlations}

Preliminary $T$ tests revealed that women and men did not differ in any of the assessed variables. Also participant's ages did not influence the results reported below. Table 3 shows descriptive statistics and correlations among the variables of Study 3. The goal variables were positively related and felt competence correlated significantly with achievement goal progress measured at T3.

\subsection{Cross sectional moderation analyses}

In order to test the cross sectional moderation effect on goal commitment at the end of the semester we entered $\mathrm{T} 3$ competence satisfaction at T3 (CS) and the implicit achievement motive (ACH) as a first step into the regression equation, followed by the CS at $\mathrm{T} 3 \times \mathrm{ACH}$ interaction term (Step 2). The main effect of felt compe tence at T3 reached significance, $\beta=.27, b=.26, s e_{\mathrm{b}}=.13, p<.05$. Additionally, the CS at T3 $\times$ ACH interaction predicted goal com mitment, $\beta=.37, b=.41, s e_{\mathrm{b}}=.15, \Delta R^{2}=.12, t(54)=2.82, p<.01$. The overall model was significant, $R^{2}=.16, F(3,54)=3.29, p<.05$. The interaction pattern was similar to that of Study 1 and Study 2: High need for achievement participants reported stronger goal commitment than individuals low in the need for achievement when their need for competence was satisfied. They also showed stronger goal commitment when they experienced competence rather than when they did not felt competent.

A parallel analysis was conducted with the variables at the first time of data collection (Step 1: CS at T2 and ACH; Step 2: CS at T2 $\times$ ACH; DV: goal commitment at T2). Although on a descriptive level the $\mathrm{CS}$ at $\mathrm{T} 2 \times \mathrm{ACH}$ interaction was similar to the interaction pattern revealed for the variables at the end of the semester, it was weaker and failed to reach significance, $\beta=.22, b=.17, s e_{\mathrm{b}}=.10$, $\Delta R^{2}=.05, \quad t(54)=1.64, \quad p=.11 \quad$ (overall model: $R^{2}=.07$, $F(3,54)=1.35, n s)$.

The same strategy of data analysis was conducted to predict goal progress. First, it was tested whether the main effects of need for competence at the end of the semester and the implicit achievement motive (Step 1) and the interaction of CS at T3 $\times \mathrm{ACH}$ (Step 2) predicted goal progress at T3. Competence satisfaction at T3 $\left(\beta=.39, b=.39, e_{\mathrm{b}}=.13\right)$ as well as the CS $\times$ ACH interaction significantly predicted goal progress, $\beta=.32, b=.36, s e_{\mathrm{b}}=.15$, $\Delta R^{2}=.09, \quad t(54)=2.44, \quad p<.05 \quad$ (overall model: $R^{2}=.19$, $F(3,54)=4.16, p<.05)$. The interaction pattern was similar to that for goal commitment at T3. Again, a parallel analysis was con ducted with the variables at the first time of data collection (Step 1: $\mathrm{CS}$ at T2 and ACH; Step 2: CS at T2 $\times$ ACH; DV: goal progress at T2). Equally to the analyses at the beginning of the semester, a main effect for CS at T2 revealed, $\beta=.20, b=.19, s e_{\mathrm{b}}=.12, p<.05$. The significant $\mathrm{CS}$ at $\mathrm{T} 2 \times \mathrm{ACH}$ interaction $(\beta=.39, b=.27$,

Table 3

Descriptive statistics and correlations (Pearson correlation) among variables of Study 3.

\begin{tabular}{|c|c|c|c|c|c|c|c|c|c|c|}
\hline & & 1 & 2 & 3 & 4 & 5 & 6 & 7 & $M$ & $S D$ \\
\hline 1 & Implicit achievement motive & 1 & .10 & .04 & -.05 & -.10 & -.03 & .13 & 3.57 & 4.26 \\
\hline 2 & Need for competence satisfaction, T2 & & 1 & .11 & -.15 & .07 & .19 & .16 & 5.14 & 0.88 \\
\hline 3 & Need for competence satisfaction, $T 3$ & & & 1 & .03 & .14 & .10 & $29^{\circ}$ & 5.37 & 0.91 \\
\hline 4 & Commitment to achievement goals, $\mathrm{T} 2$ & & & & 1 & $.65^{\cdots}$ & $.53^{\cdots}$ & $.41^{*}$ & 32.64 & 5.26 \\
\hline 5 & Commitment to achievement goals, $\mathrm{T} 3$ & & & & & 1 & $.52 \cdots$ & $.68^{\cdots}$ & 30.35 & 5.80 \\
\hline 6 & Progress of achievement goals, $\mathrm{T} 2$ & & & & & & 1 & $.66^{\cdots \cdots}$ & 11.77 & 6.38 \\
\hline 7 & Progress of achievement goals, $\mathrm{T} 3$ & & & & & & & 1 & 13.57 & 6.52 \\
\hline
\end{tabular}

. $p<.05$.

... $p<.01$. 
Table 4

Hierarchical regression of goal commitment (longitudinal, Study 3).

\begin{tabular}{|c|c|c|c|c|c|}
\hline Step & Variable & $\Delta R^{2}$ & df & $\Delta F$ & $b^{a}$ \\
\hline \multirow[t]{3}{*}{1} & Control variables & .45 & 2,55 & $22.51^{\cdots *}$ & \\
\hline & $\begin{array}{l}\text { Need for competence } \\
\text { satisfaction, T2 }\end{array}$ & & & & .19 \\
\hline & Commitment, T2 & & & & $.63^{\cdots \cdots}$ \\
\hline \multirow[t]{3}{*}{2} & Main effects & .02 & 2,53 & .93 & \\
\hline & $\begin{array}{l}\text { Need for competence } \\
\text { satisfaction (CS), T3 }\end{array}$ & & & & $.21^{\circ}$ \\
\hline & $\begin{array}{l}\text { Implicit achievement } \\
\text { motive }(A C H)\end{array}$ & & & & -.10 \\
\hline \multirow[t]{2}{*}{3} & $\mathrm{CS} \times \mathrm{ACH}$ & .08 & 1,52 & $9.42^{* *}$ & $.31^{*}$ \\
\hline & Cumulative $R^{2}$ & .51 & 5,52 & $12.72^{* \cdots}$ & \\
\hline
\end{tabular}

${ }^{a} b$ is the standardized regression coefficient in the regression equation. $p<05$.

$\cdots<.001$.

$\left.s e_{\mathrm{b}}=.10, \Delta R^{2}=.14, t(54)=3.02, p<.001\right)$ showed a very similar pattern as for the interaction at the end of the semester (overall model: $\left.R^{2}=.18, F(3,54)=3.86, p<.05\right)$.

\subsection{Longitudinal moderation analyses}

In order to test for the longitudinal effects on goal commitment, we controlled for goal commitment at T2 and competence satisfac tion at T2 (Step 1) and entered competence satisfaction (CS) at T3 and implicit achievement motivation $(\mathrm{ACH})$ as Step 2 into the regression analysis followed by the CS (at T3) $\times$ ACH interaction term (Step 3) (Table 4). The test retest effect of goal commitment at $\mathrm{T} 2, b=.61, \mathrm{se}_{\mathrm{b}}=.09, p<.001$ as well as the main effect of compe tence satisfaction at $\mathrm{T} 3$ were significant, $b=.20, \mathrm{se}_{\mathrm{b}}=.10, p<.05$. Additionally, the $\mathrm{CS} \times \mathrm{ACH}$ interaction was significant, $b=34$, $s e_{\mathrm{b}}=.11, t(52)=3.07, p<.01$. Fig. 3 illustrates that participants with a high need for achievement who felt increased competence reported more increased goal commitment compared to high achievement motivated individuals with low need for competence satisfaction and compared to individuals low in the need for achievement who also reported need for competence satisfaction. Unexpectedly, low achievement motivated individuals reported stronger goal commitment when experiencing low rather than high need for competence satisfaction.

An analogous analysis with goal progress as the dependent var iable (Step 1: goal progress at T2, CS at T2; Step 2: CS at T3, ACH;

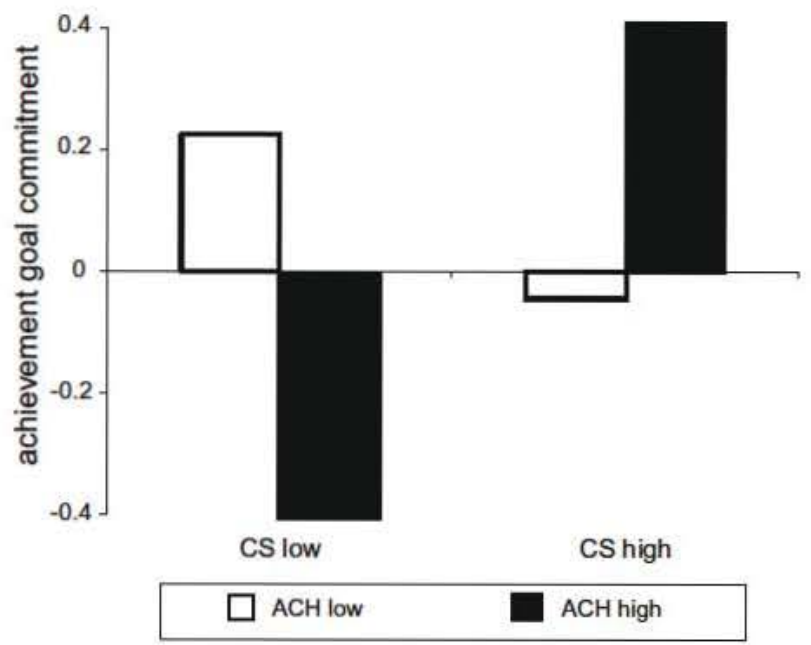

Fig. 3. Illustration of the need for competence satisfaction $\times$ implicit achievement motive effect on goal commitment (longitudinal analysis, Study 3 ).
Step 3: CS at $\mathrm{T} 3 \times \mathrm{ACH}$ ) showed that goal progress at $\mathrm{T} 2, \beta=.61$, $b=.64, s e_{b}=.10, p<.001$, as well as competence satisfaction at T3, $\beta=.29, b=.29, \mathrm{se}_{\mathrm{b}}=.10, p<.01$, predicted goal progress at T3. Additionally, the CS XACH interaction reached significance, $\beta=.21, b=.24, s e_{b}=.11, t(52)=2.07, p<.05$, indicating, that partic ipants with a high need for achievement reported more goal pro gress from the beginning to the end of the semester than individuals low in the achievement motive, but only when their competence need satisfaction scores increased. The interaction pattern was very similar to the interaction pattern of goal commit ment. The overall hierarchical regression model was significant, $R^{2}=.55, F(5,53)=12.47, p<.001\left(R^{2}\right.$ of Step $1: .44$, Step 2: .07, Step 3: .04; $\Delta F$ of Step 1: 21.51, $p<.001$, Step 2: 3.70, $p<0.5$, Step 3: 4.29, $p<.05)^{2}$

\section{Brief discussion Study 3}

Study 3 again confirmed the hypothesis that the satisfaction of the need for competence is beneficial for motivation, this time for participants' commitment to their achievement goals. Additionally we showed that competence satisfaction is also related to a perfor mance measure, in this study operationalized as goal progress. In accordance with our hypothesis, high achievement motivated indi viduals reported high goal commitment and goal progress when their need for competence was satisfied and they reported low commitment and progress when they did not feel competent. Notably, although Studies 1 and 2 found a directionally similar (but weaker) effect of competence feelings on motivation for those low in need for achievement, Study 3 found a weak crossover effect such that low achievement motivated individuals reported some what more (rather than somewhat less) goal commitment and pro gress when their competence need was not satisfied. It is possible this difference is due to the goal assessment methodology used in Study 3, which perhaps activated participant's self concepts and self presentational concerns to a greater extent than the course assessment methodologies used in Studies 1 and 2. Although fur ther research is needed here as well, we note that our perspective merely predicts that competence feelings have significantly more positive effects for high versus low achievement oriented people (which we found), not that competence always has positive effects.

\section{General discussion}

Hoping to better understand the determinants of situational motivation, the present research took a new approach to the topic of psychological needs. Specifically, we tried to integrate the self determination theory (Deci \& Ryan, 2000) and motive disposition theory perspectives on needs (e.g., McClelland, 1985) in order to understand "what gets people going." Focusing on the achieve ment domain, we first wanted to replicate the well documented positive relationship between felt competence and positive situa tional motivation. However, we also hypothesized that people high

\footnotetext{
${ }^{2}$ As in Study 2 we computed differences scores. A hierarchical regression analysis with $\mathrm{ACH}$ and increase of $\mathrm{CS}$ as Step 1 and the $\mathrm{ACH} \times$ increase of CS interaction as Step 2 in the regression equation revealed a marginal main effect for increase of $\operatorname{CS}(\beta=.23$, $\left.b=.22, s_{b}=.12, p<.10\right)$ and a significant interaction effect, $\beta=.29, b=.29, s_{b}=.13$, $t(52)=2.20, p<.05$ when predicting increase in goal progress (overall model: $R^{2}=.16$, $F(3.54)=3.39, p<.05)$. The interaction pattern is parallel to the results we reported in the text. However, a hierarchical regression analysis of increase of goal commitment revealed neither a significant main effect for increase of $\operatorname{CS}(\beta=-.10, b=-.10$, $s e_{b}=.13$ ) nor a significant $\mathrm{ACH} \times$ increase of $\mathrm{CS}$ interaction effect, $\beta=.11, b=.11$, $s e_{\mathrm{b}}=.14, t(52)=.77, n s$. (overall model: $R^{2}=.03, F(3,54)=0.47, n s$ ). The fact that the $\mathrm{ACH} \times$ increase of $\mathrm{CS}$ interaction was not significant in the difference score analysis suggests that the goal commitment finding should be treated more cautiously. However, it is also possible that problems with difference scores account for the nonsignificant effect (see Cohen et al., 2003, p. 570).
} 
in the need for achievement get more out of feeling competent than people low in the need for achievement. Three studies in dif ferent domains of human life confirmed our hypotheses, showing that individuals high in the need for achievement reported higher flow experience (Study 1), higher intrinsic motivation (Study 2), higher commitment to their goals (Study 3 ) and more goal progress (Study 3), when they experienced competence compared to when they did not experience competence and than individuals low in the need for achievement. Conversely, individuals high in the need for achievement suffered more from the frustration of the need for competence, reporting lower flow experience, intrinsic motivation, goal commitment and goal progress compared to individuals low in the need for achievement. Thus, our basic prediction, that com petence satisfaction would have different effects for those low and high in the achievement motive, was confirmed in every study; further research will be needed to explain the small variations on this pattern across studies.

Importantly, there were no main effects of the need for achieve ment just because a person is oriented in this direction does not mean they automatically thrive in that domain. Feelings of con crete competence are required to jump start the process.

The results reconfirm the universalistic assumptions of SDT, by showing the typical main effect of felt competence upon positive outcomes. However the results also newly confirm the individual difference assumptions of motive disposition theory, by showing that those more oriented towards a particular motive domain (here, achievement) are more affected by domain relevant need satisfaction (here, competence). The latter result supports Valler and's (2000) commentary arguing that individual differences can moderate basic need effects, and belies Deci and Ryan's (2000) sug gestion that this may not a fruitful place to focus research. How ever the findings also support Deci and Ryan's (2000) argument that if individual differences in needs are to be considered, they should be measured via implicit (projective) rather than by explicit (self report) methodologies. In Study 1, we found that an explicit need for achievement measure did not moderate the competence effect, whereas in all three studies, an implicit need for achieve ment measure did have such effects.

In one sense, these results support a conventional "matching" perspective which says that people benefit from getting what they want, or what matches their personality (Harackiewicz \& Sansone, 1991; Vansteenkiste, Matos, Lens, \& Soenens, 2007). However, the matching had to occur between an implicit and an explicit measure (of need for achievement and felt compe tence, respectively), rather than between two explicit measures. This suggests that it may be more important to get what matches your deeper personality, than what matches your explicit beliefs about yourself or what matches what you think you want. To pro vide a way of considering the nature of "deeper personality," Sheldon $(2004,2007)$ proposed a multi level model of personality (see also McAdams, 1996) which distinguished between self con cepts and self narratives at level 4, current goals and projects at level 3, dispositional signatures (stable traits, interests, and incli nations that vary across people) at level 2 and basic needs (evolved experiential requirements for all people) at level 1. Basic needs, which are species typical and which exist "beneath" indi vidual differences, and dispositional characteristics (including need for achievement), which represent enduring core features of different personalities, may both be construed as "deep" as pects of personality. In the current data, feelings of competence need satisfaction were particularly beneficial for people when the activity (sports or academics) mapped onto their "deeper" (implicit) motive for achievement. This finding is also consistent with Sheldon's $(2004,2007)$ claim that higher levels of personal ity can have top down moderator effects upon constructs at lower levels of personality. The results of these studies showing that motive dispositions (level 2) moderated the effects of basic needs (level 1) are consistent with Sheldon's proposals.

In principle, the results we have reported should apply to other motive dispositions besides achievement, other life domains be sides sport and student's goals, and other basic psychological needs besides competence. For example, we would predict that those high in the need for affiliation would benefit more from feelings of relatedness, and suffer more from feelings of non relatedness. What about the need for autonomy, the third basic need specified by SDT? This question is more difficult, because the need for auton omy does not have a clear analog in the motive disposition litera ture. The need for power is the other main motive within this literature, but the need for power does not map cleanly onto the need for autonomy. Although power over oneself ("autonomy" in a broader sense) is mentioned as an early stage in McClelland's (1975) developmental stages of power orientations, most motive researchers regarded the need for power as the desire to influence others in order to feel strong (higher stage in McClellands stage model) (Langan Fox \& Grant, 2007; Lewin, 1951: the power of B over A, p. 336; Sokolowski \& Kehr, 1999; Winter, 1973). In contrast, the need for autonomy reflects the individual's need to experience self determination and self governance rather than feeling gov erned by others (e.g., Deci \& Vansteenkiste, 2004). Thus, the need for power and the need for autonomy seem to represent concepts that have different foci. In any case, our perspective would predict that those higher in an implicit disposition to be self determining, if an appropriate measure existed, should benefit more from feel ings of situational autonomy. This idea remains to be tested, however.

The idea that individual differences may moderate basic need satisfaction effects suggests interesting directions for future SDT research. For example, although an impressive number of studies showed that environments supporting autonomy, competence and relatedness needs positively affect participants' well being and motivation (e.g., Baard et al., 2004; Deci \& Ryan, 2000) there is still non explained variance that is worth focusing on. We sug gest that this non explained variance is partly traced back to indi viduals who benefit to a lower degree from environments or interventions aiming at supporting, for example, autonomy or competence needs. Perhaps, due to their high need for affiliation or intimacy, some individuals would benefit more from an envi ronment supporting felt relatedness. Future research is needed to test whether the efficacy of interventions that aim at improving participants' psychological well being through satisfaction of basic needs can be improved by tailored interventions that better match with participant's individual motives.

Research is also needed to address further theoretical questions suggested by the present research and to overcome some method ological limitations of our studies. For example, it would be inter esting to test whether the reported effects also hold for different samples, e.g. for non Western individuals and for non students. From a methodological point of view it would be interesting to analyze causality rather than interpreting correlated change in the longitudinal analyses. It would be elegant to show that exper imentally manipulated need satisfaction differs in its effect on subsequent motivation in dependence of participant's need strength. Furthermore, it could be examined whether the need sat isfaction $\times$ dispositional motive interaction also influences other positive outcome variables as psychological adjustment and phys iological well being.

One important question, not answered by these data, concerns the real meaning of the term "psychological need," a term that is employed by both theoretical perspectives. What are we to make of this overlapping usage? We suggest there are two possible inter pretations of the situation. The first is that both theories address the same phenomena. If this is the case, however, then logical 
problems arise, because SDT and motive disposition theory make very different assumptions about this single phenomenon (that needs are universally and equally required by all, versus that there are large individual differences in needs; that needs function as experiential rewards for adaptive behavior, versus that needs func tion as motives impelling behavior). This would suggest that the two theories are ultimately incompatible and that one must be incorrect. The second interpretation of the situation is that the two theories address different phenomena, but by the same name (psychological needs). This would suggest that the two theories can harmoniously co exist, once the terminological confusion has been dispensed.

Our empirical data support some combination of these two interpretations. The "needs," measured by two very different methodologies, had synergistic interactions with each other thus competence need satisfaction and need for achievement are not simply the same construct. However, they must still be similar in some way, because of their similar thematic focus on competence and achievement. We suggest the following resolution: although all people have the same basic needs, people might acquire differ ent amounts of an implicit tendency to approach particular types of basic need satisfactions, perhaps as a function of their develop mental history. For example, someone who frequently experiences relatedness and communion as a child may become especially sen sitized to this dimension of experience, and thus may become skilled at creating further such experiences for herself. As another example directly relevant to this paper, a child who has many early competence experiences (perhaps because of child rearing prac tices that emphasize engagement and effectance within moder ately difficult tasks) will develop a strong need for achievement; the positive affect and reinforcement associated with such natural incentives might result in a dispositional sensitivity to respond to competence experiences (see McClelland et al., 1989 for a review).

Returning to SDT: If we view autonomy, competence, and relat edness not only as required experiences that people need to have, but also as affectively tinged natural incentives that may be cued or supported by the environment, then it is logical that some child hood environments may produce a more developed response to one type of need than to another. To use a more concrete analogy, although everyone needs food, some epicures might become par ticularly sensitized to the food need and especially benefit from and appreciate an exceptional meal. In one sense this reconcilia tion of motive disposition theory and SDT is compatible with Ryan and Deci's (2000) conceptualization of motives as individual differ ences in motivational orientations that "result from the interaction of the basic needs with the social world" (Deci \& Ryan, 2000, p. 232).

In conclusion, we suggest that the current research makes an excellent beginning towards an overdue integration of SDT and motive disposition theory, the two most prominent approaches to psychological needs, combining the main tenets of both theories to optimize the prediction of situational motivation.

\section{References}

Atkinson, J. W. (1957). Motivational determinants of risk-taking behaviour. Psychological Review, 64, 359-372.

Atkinson, J. W. (1964). An introduction to motivation. Princeton, NJ: Van Nostrand. Atkinson, J. W., \& Feather, N. T. (Eds.). (1966). A theory of achievement motivation. New York: John Wiley.

Baard, P. P., Deci, E. L., \& Ryan, R. M. (2004). Intrinsic need satisfaction: A motivational basis of performance and well-being in two work settings. Journal of Social Psychology, 34, 2045-2068.

Baumeister, R., \& Leary, M. R. (1995). The need to belong: Desire for interpersonal attachments as a fundamental human motivation. Psychological Bulletin, 117, 497-529.

Beckmann, J., \& Heckhausen, H. (2008). Motivation as a function of expectancy and incentive. In J. Heckhausen \& H. Heckhausen (Eds.), Motivation and action (pp. 99-136). Cambridge, UK: Cambridge University Press.
Brunstein, J. C. (1993). Personal goals and subjective well-being: A longitudinal study. Journal of Personality and Social Psychology, 65, 1061-1070.

Brunstein, J. C. (2008). Implicit and explicit motives. In H. Heckhausen \& J. Heckhausen (Eds.), Motivation and action (pp. 227-246). Cambridge, UK: Cambridge University Press.

Brunstein, J. C., \& Heckhausen, H. (2008). The achievement motive. In H. Heckhausen \& J. Heckhausen (Eds.), Motivation and action. Cambridge, UK: Cambridge University Press.

Brunstein, J. C., Schultheiss, O. C., \& Grässmann, R. (1998). Personal goals and emotional well-being: The moderating role of motive dispositions. Journal of Personality and Social Psychology, 75(2), 494-508.

Cohen, P., Cohen, J., West, S. G., \& Aiken, L. S. (2003). Applied multiple regression/ correlation analysis fort the behavioral sciences (3rd ed.). Hillsdale, NJ: Lawrence Erlbaum.

Csikszentmihalyi, M. (1990). Flow: The psychology of optimal experience. New York: Harper \& Row.

Csikszentmihalyi, M., Abuhamdeh, S., \& Nakamura, J. (2005). Flow. In A. J. Elliot \& C. S. Dweck (Eds.), Handbook of competence and motivation (pp. 598-608). New York: Guilford Publications.

Csikszentmihalyi, M., \& LeFevre, J. (1989). Optimal experience in work and leisure. Journal of Personality and Social Psychology, 56, 815-822.

Csikszentmihalyi, M., \& Rathunde, K. (1992). The measurement of flow in everyday life: Toward a theory of emergent motivation. In R. Dienstbier \& J. E. Jacobs (Eds.), Nebraska symposium on motivation, 1992, 40, developmental perspectives on motivation (pp. 57-97). Lincoln and London: University of Nebraska Press.

Csikszentmihalyi, M., Rathunde, K., \& Whalen, S. (1993). Talented teenagers. Cambridge: University Press.

Deci, E. L. (1971). Effects of externally mediated rewards on intrinsic motivation. Journal of Personality and Social Psychology, 18, 105-115.

Deci, E. L., \& Moller, A. C. (2007). The concept of competence. In A. J. Elliot \& C. S. Dweck (Eds.), Handbook of competence and motivation (pp. 579-597). New York: Guilford Press.

Deci, E. L., \& Ryan, R. M. (1985). Intrinsic motivation and self-determination in human behaviour. New York: Plenum.

Deci, E. L., \& Ryan, R. M. (2000). The "what" and "why" of goal pursuits: Human needs and the self-determination of behavior. Psychological Inquiry, 11, 227-268.

Deci, E. L., \& Ryan, R. M. (2008). Facilitating optimal motivation and psychological well-being across life's domains. Canadian Psychology, 49, 14-23.

Deci, E. L., \& Vansteenkiste, M. (2004). Self-determination theory and basic need satisfaction: Understanding human development in positive psychology. Ricerche di Psichologia, 27, 17-34.

Engeser, S., Rheinberg, F., Vollmeyer, R., \& Bischoff, J. (2005). Motivation, flowErleben und Lernleistung in universitären Lernsettings [Motivation, flow experience, and performance in learning settings at university]. Zeitschrift für Pädagogische Psychologie, 19, 159-172.

French, E. G., \& Chadwick, I. (1956). Some characteristics of affiliation motivation. Journal of Abnormal and Social Psychology, 52, 296-300.

Gable, S. L. (2006). Approach and avoidance social motives and goals. Journal of Personality, 74(1), 175-222.

Gable, S. L., Reis, H. T., \& Elliot, A. J. (2003). Evidence for bivariate systems: An empirical test of appetition and aversion across domains. Journal of Research in Personality, 37, 349-372.

Gagné, M. (2003). The role of autonomy support and autonomy orientation in prosocial behavior engagement. Motivation and Emotion, 27, 199-223.

Hackman, R.J., \& Lawler, E.E. 1971. Employee Reactions to Job Characteristics. Journal of Applied Psychology, 55, 259-228.

Harackiewicz, J. M., Sansone, C., \& Manderlink, G. (1985). Competence, achievement orientation, and intrinsic motivation: A process analysis. Journal of Personality and Social Psychology, 48, 493-508.

Harackiewicz, J. M., \& Sansone, C. (1991). Goals and intrinsic motivation: You can get there from here. In M. L. Maehr \& P. R. Pintrich (Eds.). Advances in motivation and achievement (Vol. 7, pp. 21-49). Greenwich, CT: JAI Press.

Hollenbeck, J. R., \& Klein, H. J. (1987). Goal commitment and the goal-setting process: Problems, prospects, and proposals for future research. Journal of Applied Psychology, 72, 212-220.

Illardi, B. C., Leone, D., Kasser, R., \& Ryan, R. M. (1993). Employee and supervisor ratings of motivation: Main effects and discrepancies associated with job satisfaction and adjustment in a factory setting. Journal of Applied Social Psychology, 23, 1789-1805.

Jackson, D. (1984). Personality research form manual. Port Huron, MI: Research Psychologists Press.

Jackson, S. A. (1995). Factors influencing the occurrence of flow state in elite athletes. Journal of Applied Sport Psychology, 7, 138-166.

Kashdan, T. B., Julian, T., Merritt, K., \& Uswatte, G. (2006). Social anxiety and posttraumatic stress in combat veterans: Relations to well-being and character strengths. Behavior Research and Therapy, 44, 561-583.

Kasser, V. G., \& Ryan, R. M. (1999). The relation of psychological needs for autonomy and relatedness to vitality, well-being, and mortality in a nursing home. Journal of Applied Social Psychology, 29, 935-954.

Kasser, V. G., Davey, J., \& Ryan, R. M. (1992). Motivation and employee-supervisor discrepancies in a psychiatric vocational rehabilitation setting. Rehabilitation Psychology, 37, 175-187.

Kehr, H. M. (2004). Implicit/explicit motive discrepancies and volitional depletion among managers. Personality and Social Psychology Bulletin, 30(3), 315-327. 
Kuhl, J., \& Scheffer, D. (1999). Der operante multi-motive-test (OMT): Manual [The operant multi-motive-test (OMT): Manual]. University of Osnabrück, Germany.

Langan-Fox, J., \& Grant, S. (2007). The effectiveness of sentence cues in measuring the big three motives. Journal of Personality Assessment, 89(2), 105-115.

Langens, T. A., \& Schmalt, H.-D. (2002). Emotional consequences of positive daydreaming: The moderating role of fear-of-failure. Personality and Social Psychology Bulletin, 12, 1725-1735.

Langens, T. A., \& Schüler, J. (2005). Written emotional expression and emotiona well-being: The moderating role of fear of rejection. Personality and Socia Psychology Bulletin, 31, 818-830.

Lewin, K. (1951). Field theory in social science. Chicago: University of Chicago Press

Locke, E. A., \& Latham, G. P. (1990). A theory of goal setting and task performance. Engelwood Cliffs, NJ: Prentice Hall.

McAdams, D. P. (1996). Personality, modernity, and the storied self: A contemporary framework for studying persons. Psychological Inquiry, 7 , 295-321.

McAdams, D. P., \& Bryant, F. B. (1987). Intimacy motivation and subjective mental health in a nationwide sample. Journal of Personality, 55, 395-413.

McClelland, D. C. (1975). Power: The inner experience. New York: Irvington.

McClelland, D. C. (1985). Human motivation. Glenview, IL: Scott, Foresman.

McClelland, D. C. (1987). Human motivation. Cambridge: Cambridge University Press.

McClelland, D. C. (1992). Motivational configurations. In C. P. Smith (Ed.), Motivation and personality: Handbook of thematic content analysis (pp. 87-99). Cambridge, UK: Cambridge University Press.

McClelland, D. C., Atkinson, J. W., Clark, R. A., \& Lowell, E. L. (1953). The achievement motive. New York: Appleton-Century-Crofts.

McClelland, D. C., \& Burnham, D. H. (1976). Power is the great motivator. Harvard Business Review, 54, 100-110.

McClelland, D. C., Koestner, R., \& Weinberger, J. (1989). How do self-attributed and implicit motives differ? Psychological Review, 96(4), 690-702.

Murray, H. A. (1938). Explorations in personality. New York: Wiley.

Murray, H. A. (1943). Thematic apperceptive test manual. Cambridge: Harvard University Press.

Pelletier, L. G., Fortier, M. S., Vallerand, R. J., Tuson, K. M., Brière, N. M., \& Blais, M. R. (1995). Toward a new measure of intrinsic motivation, extrinsic motivation, and amotivation in sports: The sport motivation scale (SMS). Journal of Sport E Exercise Psychology, 17, 35-53.

Pelletier, L. G., Fortier, M. S., Vallerand, R. J., \& Brière, N. M. (2001). Associations among perceived autonomy support, forms of self-regulation, and persistence: A prospective study. Motivation and Emotion, 25, 279-308.

Puca, R. M. (2005). The influence of the achievement motive on probability estimates in pre- and post-decisional action phases. Journal of Research in Personality, 39, 245-262.

Puca, R. M., Rinkenauer, G., \& Breidenstein, C. (2006). Individual differences in approach and avoidance movements: How the avoidance motive influences response force. Journal of Personality, 74(4), 979-1014.

Puca, R. M., \& Schmalt, H. D. (1999). Task enjoyment: A mediator between achievement motives and performance. Motivation and Emotion, 23, 15-29.

Puca, R. M., \& Schmalt, H. D. (2001). The influence of the achievement motive on spontaneous thoughts in pre- and post-decisional action phases. Personality and Social Psychology Bulletin, 27, 302-308.

Reis, H. T., Sheldon, K. M., Gable, S. L., Roscoe, J., \& Ryan, R. M. (2000). Daily wellbeing: The role of autonomy, competence, and relatedness. Personality and Social Psychology Bulletin, 26, 419-435.

Richer, S., Blanchard, C. M., \& Vallerand, R. J. (2002). A motivational model of turnover. Journal of Applied Social Psychology, 32(10), 2113-2989.

Rheinberg, F., \& Vollmeyer, R. (2003). Flow Erleben in einem Computerspiel unter experimentell variierten Bedingungen [Flow experience in a computer game under experimentally controlled conditions]. Zeitschrift für Psychologie, 21 161-170.
Rheinberg, F., Vollmeyer, R., \& Engeser, S. (2003). Die Erfassung des Flow Erlebens [Measuring flow experience]. In J. Stiensmeier-Pelster \& F. Rheinberg (Eds.) Diagnostik von Motivation und Selbstkonzept (pp. 261-279). Göttingen: Hogrefe.

Ryan, R. M., \& Deci, E. L. (2000). The darker and brighter sides of human existence: Basic psychological needs as a unifying concept. Psychological Inquiry, 11, 319-338.

Schmalt, H. D. (1999). Assessing the achievement motive using the grid technique. Journal of Research in Personality, 33, 109-130.

Schneider, K., \& Schmalt, H. D. (2000). Motivation [Motivation]. Stuttgart, Germany: Kohlhammer.

Schultheiss, O. C., \& Hale, J. (2007). Implicit motives modulate attentional orienting to facial expressions of emotion. Motivation and Emotion, 31, 13-24.

Schüler, J. (2007). Arousal of flow experience in a learning setting and its effects on exam-performance and affect. Zeitschrift für Pädagogische Psychologie, 21 217-227.

Schüler, J., Job, V., Fröhlich, S., \& Brandstätter, V. (2008). A high implicit affiliation motive does not always make you happy. Motivation and Emotion, 32, 231-242.

Sheldon, K. M. (2004). Optimal human being: An integrated multi-level perspective. Mahwah, NJ: Erlbaum.

Sheldon, K. M. (2007). Considering the optimality of personality: Goals, selfconcordance, and multi-level personality integration. In B. Little, K. SalmeloAro, J. Nurmi, \& \& S. Phillips (Eds.), Personal projects pursuit: Goals, action and human flourishing (pp. 355-374). Mahway, NJ: Lawrence Erlbaum.

Sheldon, K. M., Elliot, A. J., Kim, Y., \& Kasser, T. (2001). What is satisfying about satisfying events? Testing 10 candidate psychological needs. Journal of Personality and Social Psychology, 80, 325-339.

Sheldon, K. M., \& Krieger, L. S. (2007). Understanding the negative effects of lega education on law students: A longitudinal test of self-determination theory. Personality and Social Psychology Bulletin, 33, 883-897.

Sheldon, K. M., Ryan, R. M., \& Reis, H. T. (1996). What makes for a good day? Competence and autonomy in the day and in the person. Personality and Social Psychology Bulletin, 22, 1270-1279.

Sokolowski, K., \& Kehr, H. M. (1999). Zum differentiellen Einfluß von Motiven auf die Wirkungen von Führungstrainings (MbO) [Differential impact of motive dispositions on the effects of management training (MbO)]. Zeitschrift für Differentielle und Diagnostische Psychologie, 20, 192-202.

Sokolowski, K., Schmalt, H.-D., Langens, T. A., \& Puca, R. M. (2000). Assessing achievement, affiliation, and power motives all at once - The multi-motive grid (MMG). Journal of Personality Assessment, 74, 126-145.

Stumpf, H., Angleitner, A., Wieck, T., Jackson, D. N., \& Beloch-Till, H. (1985). Deutsche personality research form (PRF) [German personality research form (PRF)] Göttingen, Germany: Hogrefe.

Vallerand, R. J. (2000). Deci and Ryan's self-determination theory: A view from the hierarchical model of intrinsic and extrinsic motivation. Psychological Inquiry, $11,312-318$.

Vallerand, R. J., \& Reid, G. (1984). On the causal effects of perceived competence on intrinsic motivation: A test of cognitive evaluation theory. Journal of Sport Psychology, 6, 94-102.

Vansteenkiste, M., \& Deci, E. L. (2003). Competitively-contingent rewards and intrinsic motivation: Can losers remain motivated? Motivation and Emotion, 27 273-299.

Vansteenkiste, M., Matos, L., Lens, W., \& Soenens, B. (2007). Understanding the mpact of intrinsic versus extrinsic goal framing on exercise performance: The conflicting role of task and ego involvement. Psychology of Sport and Exercise, 8 771-794.

Willett, J. B. (1997). Measuring change: What individual growth modeling buys us. In E. Amsel \& K. A. Renninger (Eds.), Change and development. Issues of theory, method and application. Mahwah: Lawrence Erlbaum Associates.

Wilson, P. M., Rogers, W., Rodgers, W. M., \& Wild, T. C. (2006). The psychological need satisfaction in exercise scale. Journal of Sports and Exercise Psychology, 28(3), 231-251

Winter, D. G. (1973). The power motive. New York: The Free Press. 